Journal of the Egyptian Society of Parasitology, Vol.43, No.1, April 2013

J. Egypt. Soc. Parasitol., 43(1), 2013: 287 - 294

\title{
RISK FACTORS ASSOCIATED WITH INTESTINAL PARASITIC INFECTIONS AMONG CHILDREN
}

\section{By}

GEHAD T. EL-SHERBINI AND MOSTAFA MOHAMED ABOSDERA

Department of Parasitology, Faculty of Pharmacy, October 6 University

Cairo, and Department of Pediatric, Faculty of Medicine, Sohag University, Egypt

\begin{abstract}
Intestinal parasites are endemic worldwide and have been described as constituting the greatest single worldwide cause of illness and disease. The effective prevention and control of intestinal parasitic infections requires identification of local risk factors, particularly among high-risk groups. This study retrospectively analyzed demographic factors that may affect the prevalence of intestinal parasites among school children. Interviews, observation, and anthropometric indices assessment were used to identify the risk factors. The findings of the study showed that young age, female gender, and severe malnutrition, Poverty, illiteracy, poor hygiene, lack of access to potable water and hot and humid tropical climate are the factors associated with intestinal parasitic infections all correlated positively with increased rates of infection. Clinical visits were performed on 650 school children aged 5-15 years over a four-year period (2010-2013) in the Nahya Village, Giza Governorate. Stool specimens were examined using the formal ether concentration technique. Data were analysed using the SPSS statistical software. The results suggest that the prevalence of gastrointestinal parasites among young children is highly dependent on the specific species of the parasite.
\end{abstract}

Key words: Egypt, Intestinal parasites Children, Retrospective studies.

\section{Introduction}

Intestinal parasitic infections (IPIs) are globally endemic and have been described as constituting the greatest single worldwide cause of illness and disease (Curtale et al, 1998; Steketee, 2003). The WHO estimates that over two billion people in the world are infected with at least one form of enteropathogen, the majority of who reside in developing countries and in areas of poor hygiene (Tian et al, 2012). School age children are one of the groups at high-risk for intestinal parasitic infections. The adverse effects of intestinal parasites among children are diverse and alarming. Intestinal parasitic infections have detrimental effects on the survival, appetite, growth and physical fitness, school attendance and cognitive performance of school age children (Green et al, 2011). Identification of local risk factors in different regions/localities is a prerequisite to develop appropriate control strategies. 
IPIs are linked to lack of sanitation, lack of access to safe water and improper hygiene; therefore they occur wherever there is poverty. IPIs deprive the poorest of the poor of health, contributing to economic instability and social marginalization. The poor people of under developed nations experience a cycle where under nutrition and repeated infections lead to excess morbidity that can continue from generation to generation (Novak et al, 2012). People of all ages are affected by this cycle of prevalent parasitic infections; however, children are the worst affected (Curtale et al, 1998). A. lumbricoides, G. lamblia, E. histolytica, H. nana, and $B$. hominis are a significant publichealth problem in rural area and in the developing world as a whole. A. lumbricoides infects an estimated 1.472 billion people worldwide, causing morbidity to 335 million and 60,000 deaths annually (WHO, 2006). Helminthes disproportionately impacts the children health, potentially causing malabsorption of nutrients, loss of appetite, impaired growth, vomiting, anemia, anorexia, and, in extreme cases, death by the intestinal obstructions (Zieliński and Czarkowski, 2011).

Also, G. lamblia is among the most common intestinal protozoa in the world, infecting more than 200 million people worldwide, although it is markedly more prevalent in developing countries (Zaki et al, 2003). Infection requires ingestion of as few as 10 viable cysts and is easily spread through contamination of piped water. Painful gas, bloating, fatty diarrhea, and general epigastric pain are frequently asso- ciated with the infection. E. histolytica is the major cause of the amoebic dysentery in the world, infecting an estimated 480 million people worldwide and causing about 70,000 deaths annually (Hotez et al, 2008). Symptoms of infection include the abdominal pain, bloody stools, severe diarrhea, weight loss, and fatigue, and fatality may occur if the amoeba reaches the liver and is left untreated. Both Hymenolepis nana and Enterobius vermicularis infect about millions of people worldwide (Bayoumy et al, 2010). Symptoms of infection include also abdominal pain, loss of appetite, itching around the anus, irritability, and diarrhea. Little is known on the epidemiology of $B$. hominis, although it is a contributing risk factor for iron deficiency anemia (El Deeb et al, 2012). B. hominis has a worldwide distribution and is most prevalent in areas of low socioeconomic status. Symptoms associated with infection range from abdominal pain and constipation to diarrhea, vomiting, fatigue, nausea, and fever. Hence the aim of this study was to identify demographic variables potentially associated with increased rates of gastrointestinal parasite infection among the school children. It is hoped that the outcome results of this study will help improve the effectiveness in designing and promoting health initiatives and in aiding other public-health policy-makers active in Egypt Highlands.

\section{Subjects, Materials and Methods}

A cross sectional parasitological survey was conducted in children enrolled in primary schools in Nahya village Giza governorate Egypt. Children from 
the schools were living under poor environmental sanitation and low socioeconomic status. There was no adequate safe water supply in the areas. A simple random sample of 650 children aged 5-15 years was collected. The study used structured pre-tested questionnaire, anthropometric tools and stool tests to obtain epidemiological and disease data. Data were analyzed using appropriate descriptive, univariate and multivariable logistic regression methods. The research was conducted among the seven schools found in the valley. To select the sample children, the students were first stratified according to their educational level, the sample children were selected using the systematic random sampling techniques by using class rosters as the sample frame. A pre-tested questionnaire based on known risk factors was developed and modified. The interview included information such as age, family size, source and storage conditions of drinking water, access to latrines in their homes, and yes or no choice questions for common signs and symptoms of parasitic infections during the past month. At the time of conversation, interviewers also inspected the foot wear and the fingernails of the students. At the end of the day all the questionnaires were checked for accuracy and completeness. Children were supplied with labeled plastic containers, waterproof papers, and applicator sticks, and instructed to bring proper stool samples the next day. All the specimens were checked for their label, quantity, time, and procedure of collection. Samples that complied with the study were emulsified in $10 \%$ formalin solution and transported lab. Stool examinations were done by formal ether concentration technique ( Gad et al, 2011). SPSS, Windows version 11 was used for data analysis (Chandra Shekar and Reddy2008). Descriptive and inferential (chi-square) statistical tests were used. The significance of the differences in frequency distribution was tested by using chi-square analyses. Pvalues less than 0.05 were considered statistically significant.

Ethical Considerations: The head of the District Education Authority and the school Headmaster gave their written consent before the study. The study purpose was explained to the school community and participation of the children was on voluntary basis, parents were informed about the results of children's stool examination, and the health information was also given. All children positive for $S$. mansoni ova were successfully treated with a single dose of Mirazid ${ }^{\circledR}$ (El Baz et al, 2003) or Albendazole ${ }^{\circledR}$ (Abdel-Tawab et al, 2009). The children infected with other helminthes were treated with the standard regiment at the Ministry of Health Center.

\section{Result}

Out of 722 children were invited to participate and 650 provided proper stool samples, and complete information. Among them $420 \quad(64.6 \%)$ were males and 230 (35.4\%) females. Children mean age was 11.2 years. Out of 650 school child examined nine species of intestinal parasite were identified with an overall prevalence of $63.8 \%$ (415 out of 650 children) 
Table 1: Prevalence of intestinal parasite among school children, according to sex

\begin{tabular}{|c|c|c|c|c|c|c|}
\hline \multirow[t]{2}{*}{ Parasites } & \multicolumn{2}{|c|}{ male $\mathrm{N}=251$} & \multicolumn{2}{|c|}{ Female N=164 } & \multicolumn{2}{|c|}{ Both sex $\mathrm{N}=415$} \\
\hline & No & $\%$ & No & $\%$ & No & $\%$ \\
\hline Hymenolepis nana & 13 & (5.4) & 5 & (3.0) & 18 & $(4.3)$ \\
\hline Hookworm & 6 & (2.4) & 3 & (1.8) & 9 & $(2.1)$ \\
\hline Schis. mansoni* & 5 & (1.9) & 1 & $(0.6)$ & 6 & (1.4) \\
\hline A.l umbricoides & 10 & (3.9) & 5 & (3.0) & 15 & (3.6) \\
\hline T. trichiura & 4 & (1.6) & 5 & (3.0) & 9 & (2.1) \\
\hline E. vermicularis & 4 & (1.6) & 2 & $(1.2)$ & 6 & $(1.4)$ \\
\hline E.histolytica & 15 & (5.9) & 6 & (3.6) & 21 & $(5.0)$ \\
\hline S. stercoralis & 2 & $(0.7)$ & - & & 2 & $(0.2)$ \\
\hline G. lamblia & 19 & (7.5) & 8 & $(4.8)$ & 20 & $(4.8)$ \\
\hline Overall prevalence & 78 & (31) & 35 & $(21.3)$ & 113 & (27.2) \\
\hline
\end{tabular}

*Difference statistically significant $(\mathrm{p}<0.05)$.

Table 2: Prevalence of single and mixed infections in subjects

\begin{tabular}{|l|cc|}
\hline Type of infection & \multicolumn{2}{|c|}{ Parasite } \\
\cline { 2 - 3 } & No & $\%$ \\
\hline None & 235 & 36.2 \\
Single infection & 205 & 49.4 \\
Double infection & 188 & 45.3 .8 \\
Triple infection & 22 & 5.30 \\
\hline
\end{tabular}

Table 3: Analysis for factors potentially associated with parasites among children

\begin{tabular}{|c|c|c|c|c|}
\hline \multirow[t]{2}{*}{ Risk factor } & \multicolumn{2}{|c|}{ Total positive $n=415$} & \multicolumn{2}{|c|}{ Total negative $\mathrm{n}=235$} \\
\hline & No & $\%$ & No & $\%$ \\
\hline Male & 251 & 38.6 & 169 & 26 \\
\hline Female & 164 & 25.2 & 66 & 10.2 \\
\hline \multicolumn{5}{|l|}{ Age } \\
\hline $5-9$ & 320 & 49.2 & 180 & 27.7 \\
\hline $10-15$ & 95 & 14.6 & 55 & 8.5 \\
\hline \multicolumn{5}{|l|}{ Practice of finger nail term } \\
\hline Yes & 25 & 3.8 & 205 & 31.5 \\
\hline No & 390 & 60.1 & 30 & 4.6 \\
\hline \multicolumn{5}{|c|}{$\begin{array}{l}\text { Washing anal area by hands after defecation } \\
\text { Yes }\end{array}$} \\
\hline \multirow[t]{2}{*}{ No } & 360 & 55.3 & 35 & 5.4 \\
\hline & 55 & 8.5 & 200 & 30.8 \\
\hline \multicolumn{5}{|l|}{ Eating raw\& unwashed vegetables } \\
\hline Yes & 370 & 56.9 & 195 & 30 \\
\hline No & 45 & 6.9 & 40 & 6.2 \\
\hline \multicolumn{5}{|l|}{ Hand washing before eating } \\
\hline Yes & 52 & 8 & 198 & 30.5 \\
\hline No & 363 & 55.8 & 37 & 5.7 \\
\hline \multicolumn{5}{|l|}{ Water source } \\
\hline Pipe & 156 & 24 & 200 & 30.8 \\
\hline River & 259 & 39.8 & 35 & 5.4 \\
\hline \multicolumn{5}{|l|}{ Toilet paper } \\
\hline Yes & 2 & 0.3 & 35 & 5.4 \\
\hline No & 413 & 63.5 & 200 & 30.8 \\
\hline \multicolumn{5}{|l|}{ Mother education } \\
\hline Yes & 40 & 6.2 & 195 & 30.0 \\
\hline No & 375 & 57.6 & 40 & 6.2 \\
\hline \multicolumn{5}{|l|}{ Open field defecation } \\
\hline Yes & 320 & 49.2 & 38 & 5.9 \\
\hline No & 95 & 14.6 & 197 & 30.3 \\
\hline
\end{tabular}




\section{Discussion}

The epidemiological study on the prevalence of infection of intestinal parasites indifferent regions/ localities is a primary objective to identify the high-risk communities and formulate appropriate intervention. In the line with this view, the present study attempted to assess the prevalence of different intestinal parasitic infections and associated risk factors in school children in a village in Giza governorate Egypt. The results showed the occurrence of several intestinal parasites of the public health importance among the schoolchildren.

In this study, the overall prevalence rate of intestinal parasite was found to be $(63.8 \%)$.This high prevalence could be due to the place and living standard of study subjects or due to a reflection of the local endemicity and geographic condition of the study area. Environmental sanitation and personal hygiene of study subjects probably play an important role for the higher prevalence rate of intestinal parasite. We estimated the prevalence of intestinal parasitic infections (IPIs) and factors associated with IPIs among children 5-15 years of age from an urban slum. This study also showed that age of the child, rented household were significantly associated with intestinal parasitic infection (IPIs).

A large part of the latrines in the schools visited were inappropriately maintained water sources were identified as a risk factor for Giardia, as this intestinal protozoon species is commonly transmitted by ingesting cysts persisting in contaminated water or from person-to-person through the fecal-oral route (El-Shazly et al, 2004). The study data indicated that the use of drinking water from improved sources (public well/standpipe) is a protective factor for infections with $E$. histolytica, $G$. intestinalis and $H$. nana. The similar data were observed for $H$. nana in AlFayoum (El-Mohamady et al, 2006).

Tap water was associated with low infection prevalence of $G$. intestinalis compared to the use of surface water in a school based survey (Badawy et al, 2012). A study from Mexico City identified the storing of drinking water in unprotected containers (cisterns, tanks and bucks) as a risk factor for $G$. intestinalis (Cifuentes et al, 2004).

In the present study, there were few limitations. First, only one stool sample was collected from each participant. Previous research has shown that multiple stool sampling enhances the sensitivity of helminthes and intestinal protozoa diagnosis (Knopp et al, 2008). Indeed, the adhesive tape method is recommended for $E$. vermicularis diagnosis, but there are compliance issues with this method (Jeandron et al, 2010). For S. steroralis, the Agar plate culture method was a must (Massoud et al, 2006). To partially overcoming these shortcomings, we prepared duplicate preserved 1-2 $\mathrm{g}$ of stool that was subjected to an additional diagnostic approach, the ether-concentration method. Data from both methods combined were considered as diagnostic 'gold' standard. Third, no attempt was made to investigate seasonality. It was speculate that the prevalence of parasitic infections might be higher in summer 
when children spend more time outside and eat more frequently unwashed vegetables and fruits from the rural areas (Gungoren et al, 2007). The present diagnostic sensitivity was improved by taken three consecutive stool samples but this was not done. Age is an important risk factor for IPIs (Houweling et al, 2003) and school going children have been reported to be at highest risk for IPIs. In the present study, an increasing dose-response association between age and IPIs within age group of 5 to 7 years was identified. This could be due to the fact that child grows older the exposure to many of the risk factors for IPIs increases (Iacono et al, 2005). The linear association of age within the range needs further exploration through prospective studies. The lower socioeconomic status (SES) is also a risk factor for IPIs (Nematian et al, 2004). The effect of SES on risk of infectious diseases in general, and parasitic infections in particular, is complex in nature and could be attributed to several other factors such as lack of access to clean water, poor hygienic environment, lack of access to education due to financial constraints and overcrowded conditions (Harpham, 2002;). It was planned to conduct stool sample testing within two hours of collection, however, due to logistic constraints, it was delayed at times from 3 to 6 hours as a result protozoans could not detect the invasive form.

Among the potential risk factors explored using univariate analysis, mothers educational level, hand washing practice before and after meals, habit of eating raw/unwashed vegetables, drink- ing water, open field defecation and finger nail condition had statistically significant association to any intestinal parasite infections identified. No doubt, Mothers' younger age, higher level of education, moderate socioeconomic family status, less number of children, mother using quality control all contribute to minimizing risk factors of intestinal parasitosis for all the family members (El-Dosoky, 2012).

\section{Conclusions}

The present study provides new insight into school-aged children's infection status with intestinal parasite. School latrines and targeted health education programs, better hygiene and improved sanitation.

Treatment with Mirazid or Albendazole control soil transmitted helminthiasis, whereas metronidazole should be utilized against the two pathogenic intestinal protozoa. Previous research showed that carefully designed schoolbased hygiene programs contributed to reduce infection and re-infection rates. Further studies are warranted to assess the true public health burden due to $H$. nana infection to guide future control efforts against these helminthes, which represented the predominant species in the study area. Effective poverty reduction programs and promotion of deworming could reduce intestinal parasite carriage.

Consequently, the Governmental Authorities should enhance the activity of poverty reduction programs. There is a bad need for mass scale campaigns to create awareness about health hygiene and infection control. 


\section{References}

Abdel-Tawab, AM, Bradley, M, Ghazaly, EA, Horton, J, el-Setouhy, M, 2009: Albendazole and its metabolites in the breast milk of lactating women following a single oral dose of albendazole. Br. J. Clin. Pharmacol. 68, 5: 737-42.

Badawy, A, Gneidy, M, Ghoniemy, A, 2012: Acute diarrhea among military recruits. J. Egypt. Soc. Parasitol. 42, 2:309-20.

Bayoumy, AM, Mohammed, KA, Shahat, SA, Ghannam, MM, Gazy, MS, 2010: Role of parasites among chronic diarrheic patients. J. Egypt. Soc. Parasitol. 40, 3:679-98.

Chandra Shekar, BR, Reddy, C, 2008: A five-year retrospective statistical analysis of maxillofacial injuries in patients admitted and treated at two hospitals of Mysore city. Indian J. Dent. Res. 19, 4:304-8.

Cifuentes, E, Suarez, L, Espinosa, M, Juarez, L, Martinez, A, 2004: Risk of Giardia intestinalis infection in children from an artificially recharged groundwater area in Mexico City. Am. J. Trop. Med. Hyg. 71:65-70.

Curtale, F, Pezzotti, P, Sharbini, AL, Maadat, H, Ingrosso, $P$, et al, 1998: Knowledge, perceptions and behaviour of mothers toward intestinal helminths in Upper Egypt: implications for control. Hlth. Policy Plan13:423-32.

El Baz, MA, Morsy, TA, El Bandary, MM, Motawea, SM, 2003: Clinical and parasitological studies on the efficacy of mirazid in treatment of schistosomiasis haematobium in Tatoon, Etsa
Center, Al Fayoum Governorate. J. Egypt. Soc. Parasitol. 33, 3:761-76.

El Deeb, HK, Salah-Eldin, H, Khodeer, S, 2012: Blastocystis hominis as a contributing risk factor for development of iron deficiency anemia in pregnant women. Parasitol Res. 110, 6: 2167-74.

El-Dosoky, RS, 2012: Home-related injuries among children: Knowledge, attitudes and practice about the first aid among rural mothers. East. Mediterr. Hlth. J. 18, 10:1021-7.

El-Mohamady, H, Abdel-Messih, IA, Youssef, FG, Said, M, Farag, H, et al, 2006: Enteric pathogens associated with diarrhea in children in Fayoum, Egypt. Diag. Microbiol. Infect. Dis. 56, $1: 1-5$.

El-Shazly, AM, Mowafy, N, Soliman, M, El-Bendary, M, Morsy, ATA, et $\boldsymbol{a l}$, 2004: Egyptian genotyping of Giardia lamblia. J. Egypt. Soc. Parasitol. 34, 1:265-80.

Gad, YZ, Ahmad, NA, El-Desoky, I, Arafa, MM, Farag, RE, 2011: Colorectal schistosomiasis: Is it still endemic in delta Egypt, early in the third millennium. Trop. Parasitol. 1, 2:108-10.

Green, HK, Sousa-Figueiredo, JC, Basáñez, MG, Betson, M, Kabatereine, NB, et al, 2011: Anaemia in Ugandan preschool-aged children: the relative contribution of intestinal parasites and malaria. Parasitol. 138, 12:153445.

Gungoren, B, Latipov, R, Regallet, G, Musabaev, E, 2007: Effect of hygiene promotion on the risk of reinfection rate of intestinal parasites in chil- 
dren in rural Uzbekistan. Trans. R. Soc. Trop. Med. Hyg.101:564-9.

Harpham, T, 2002: Measuring child poverty and health: a new international study. J. Trop. Pediatr. 48:128-30.

Hotez, PJ, Brindley, PJ, Bethony, J M, King, CH, Pearce, EJ, et al, 2008: Helminth infections: the great neglected tropical diseases. J. Clin. Invest. 118:1311-21.

Houweling, TA, Kunst, AE, Mackenbach, JP, 2003: Measuring health inequality among children in developing countries: does the choice of the indicator of economic status matter? Int. J. Equity Hlth. 2:8-12.

Iacono, G, Merolla, R, D'Amico, D, Bonci, E, Cavataio, F, et al, 2005: Gastrointestinal symptoms in infancy: a population-based prospective study. Dig. Liver Dis. 37:432-8.

Jeandron, A, Abdyldaieva, G, Usubalieva, J, Ensink, JHJ, Cox, J, et al, 2010: Accuracy of the Kato-Katz, adhesive tape and FLOTAC techniques for helminth diagnosis among children in Kyrgyzstan. Acta Trop. 116:185-92.

Knopp, S, Mgeni, AF, Khamis, IS, Steinmann, P, Stothard, JR, et al, 2008: Diagnosis of soil-transmitted helminths in the era of preventive chemotherapy: effect of multiple stool sampling and use of different diagnostic techniques. PLoS. Negl. Trop. Dis. 2: e331.

Massoud, AM, El-Shazly, AM, Awad, SE, Morsy, ATA, Sadek, GS, Morsy, TA, 2006: New trends in diagnosis and treatment of chronic intestinal strongyloidiasis stercoralis in Egyptian patients. J. Egypt. Soc. Parasitol. 36, 3: 827-44.

Nematian, J, Nematian, E, Gholamrezanezhad, A, Asgari, AA, 2004: Prevalence of intestinal parasitic infections and their relation with socio-economic factors and hygienic habits in Tehran primary school students. Acta Trop. 92: 179-86.

Novak, C, Lingam, R, Coad, J, Emond, A, 2012: Providing more scaffolding': parenting a child with developmental co-ordination disorder, a hidden disability. Child Care Hlth. Dev. 38, 6: 829-35

Steketee, RW, 2003: Pregnancy, nutrition and parasitic diseases. J. Nutri. 133:S1661-7.

Tian, LG, Chen, JX, Wang, TP, Cheng, GJ, Steinmann, P, et al, 2012: Coinfection of HIV and intestinal parasites in rural area of China. Parasit. Vectors 13, 5:36-42.

WHO, 2006: Software for assessing growth and development of the world's children. Geneva, Switzerland.

Zaki, A, Bassili, A, Amin, G, Aref, T, Kandil, M, et al, 2003: Morbidity of schistosomiasis mansoni in rural Alexandria, Egypt. J. Egypt. Soc. Parasitol. 33, 3:695-710.

Zieliński, A, Czarkowski, MP, 2011: Infectious diseases in Poland in 2009. Przegl. Epidemiol. 65, 2:171-9. 